\title{
Horse chestnut (aesculus hippocastanum) for venous insufficiency
}

Volume 5 Issue 3 - 2017

\section{Botanical monograph}

Native to Asia and southeastern Europe (especially northern Greece, Albania, and Turkey), "The large leaves of horse chestnut (Aesculus hippocastanum) are divided into five or seven leaflets, spreading five fingers from the palm of the hand, and have - their margins finely toothed. The flowers grow in erect, dense racemes, mostly white with tinges of red. A showy floral display blooms in April or May in the northeastern United States, and earlier in the West The ripe horse chestnuts are gathered from the ground as they fall from the trees in autumn- They are hulled from the spiny capsule, which contains usually three large seeds that resemble edible chestnuts, and which are utilized for medicine.

The plant constituents utilized medicinally come from the fruits. They are a complex mixture of triterpenoid saponin glycosides and lactone glycosides, including protoaesigenin, barringeogenol-C, (reference 2) hippocaesculin, 6-E-glucoside-7-hydroxy coumarin, and others, collectively called aescin (or occasionally escin). It also provides aesculic acid, aesculinic acid, an appreciable level of flavonoids (esculin, esculetin, rutin, kaempferol), tannins, starches, magnesium, sodium, iron, manganese, cobalt, iodine, and sterols.

\section{General activity}

Today, horse chestnuts provide an important activity, specifically for the veins, and are used in a number of circulatory problems. These include varicose veins, hemorrhoids, blood clots, and phlebitis conditions. Horse chestnut also accelerates wound- healing. An internally used extract sold in Europe is popular for arthritis and other complaints. Furthermore, mounting scientific and clinical data show that horse chestnuts have anti-i.

\section{Historical perspective}

Horse chestnut was long used by the Turks, not for their own ailments, but for their horses' respiratory problems. They referred to the horse chestnut as "AtKastan." It was also used as a specific remedy for horses suffering from "broken wind' coughing, and fevers. In addition, horse chestnut was believed to reduce the pain and inflammation of rheumatic ailments. Poultices of the seeds were used topically to treat non- healing or recalcitrant skin ulcers and other dermatitis- like conditions.

The name Aesculus (from esca, food) applies to its use as fodder for livestock. Horse chestnut was never used as human food.' Hippocastanum, according to Grieve, may be derived from a translation of At-Kastan due to "its ability to cure cattle and horses of broken-windedness and coughs:' "Horse" may also be a derivative of the Welsh word "gwres" (pronounced like "horse"), which means hot, fierce, bitter, and pungent, as opposed to the sweet chestnut, which it resembles".

By the 1740 s, horse chestnut was widely cultivated and introduced

\author{
Eugene Zampieron Zampieron \\ University of Bridgeport College of Naturopathic Medicine, \\ USA \\ Correspondence: Eugene Zampieron, University of \\ Bridgeport College of Naturopathic Medicine, 413 Grassy Hills \\ Rd,Woodbury, CT 06798, USA, Tel (203) 263-2970, \\ Email kscndı@hanmail.net
}

Received: July 13, 2016 | Published: February 01, 2017

in Europe and the Americas as an ornamental. Shortly after, native people began utilizing the fruits of these stately trees as a human medicament. When crushed, the nuts, leaves, and bark were used in medicinal preparations, and especially eased the pain and inflammation of hemorrhoids and soothed achiness and weariness in the legs. ${ }^{2}$

The Eclectic physicians at the turn of the 20th century used what they termed 'Hippocastanum' as medicine. The bark was used at a dose of 1 to 60 grains (Igram=15.5 grains). The specific indications were general malaise, vascular engorgement with dull aching pain and fullness, leg throbbing, fullness in the right upper quadrant, torpor of the sublingual veins, varicose veins, disturbances of the rectum, nonbleeding hemorrhoids/piles when full, purple, and painful. ${ }^{3}$

\section{Pharmacological properties pharmacokinetics} and

Aescin has been theorized to improve the circulation through the veins. Klemm et al., ${ }^{4}$ illustrated that aescin decreases blood viscosity, improves blood hemodynamics, and reduces the incidence of thromboembolic disease, even 14days after the study participants' discontinuation of the treatment. ${ }^{4}$ Aescin can also enhance normal venous tone, ${ }^{5}$ thereby assisting in the proper return of blood and fluids back to the heart from the periphery. In addition, aescin has been clinically demonstrated to reduce edema after trauma and surgical disruption of the circulatory system.

The German Commission E monograph lists aesculus as having "anti-exudative and vascular-tightening effects.' Some evidence indicates that aesculus reduces the activity of lysosomal enzymes. This reduction is intensified in chronic pathological conditions of the veins, so that the breakdown of the glycocalyx (monopoly saccharides) in the region of the venous walls is inhibited, ${ }^{6}$ thus contributing to sustained venous tone.

H.W Kreysel et at., ${ }^{7}$ Published a paper that identified the enzymes inhibited by horse chestnut as glycosaminoglycans hydrolase enzymes (elastase, hyaluronidase, B-N-acetyl-glucosarriinidase, B-glucuronidase, and arylsulphatase). In this study, continuous treatment of 15 varicose vein in patients with a non-standardized 
extract of horse chestnut seeds $(900 \mathrm{mg} /$ day for 12 consecutive days) led to a significant $(\mathrm{p}<0.01)$ reduction in the activities of these enzymes. The crude drug extract resulted in the same magnitude of enzyme reduction for each of the enzymes, which "prompted the hypothesis that the crude drug extract of horse chestnut does not inhibit each enzyme protein individually, but acts via a protective effect towards strengthening the lysosomal membranes from premature or excessive rupture. ${ }^{7}$ Thus, the main cause of edema in chronic venous insufficiency is the transcapillary escape or leakage of low-molecular proteins, followed by electrolytes and water into the interstitial cellular areas. The connective tissue of the walls has lost their patency due to a host of underlying etiologies, which culminate in the lysosomal enzymatic degradation of the vein's connective tissue.

\section{Clinical research}

Horse chestnut extracts have been the subject of a number of quality clinical reviews, many of which have been double-blind, placebo-controlled trials.

\section{Non-pathological edema of the legs}

Swelling of the legs is not necessarily a symptom of disease, but it can be a consequence of the fact that people were not meant to be immobile for long hours. It can be found in patients with normal healthy veins, if they are subjected to extreme orthostatic load (e.g., crossing the legs for a lengthy time on a long, cramped, intercontinental flight).

Mounting scientific and clinical data show that horse chestnuts have anti-inflammatory properties and can increase the strength and tone of the veins.

\section{Comparison of leg compression stocking versus aesculus}

The Lancet published a study conducted at the University of Heidelberg, Germany. ${ }^{4}$ Standard medical intervention of elastic support therapy (via compression stockings) was compared to a placebo and $300 \mathrm{mg}$ of an aesculus extract, standardized to contain $50 \mathrm{mg}$ aescin, given twice daily in 240 patients with diagnosed CVI. After 12 weeks of therapy, analysis of lower leg volume showed that compression therapy and aesculus were almost identical in effect and far surpassed that of placebo.

The researchers pre-randomized the group using the compression therapy, so that non-compliant patients who did not want to wear the appliance were eliminated. Mean leg edema volume in CVI patients was estimated at $220 \mathrm{ml}^{8-13}$

The 12-week course of aesculus thus resulted in a $25 \%$ reduction of mean edema volume, as measured by water volume displacement plethysmography. Considering that in "real life" the compliance of wearing compression hosiery is poor, the authors felt that aesculus was an efficacious alternative to compression therapy. ${ }^{4}$

Maximum circumference of the foot around the heel (H-size) and the smallest circumference around the ankle were measured in 19 participants without a history of venous disease or chronic venous insufficiency (CVI). Measurements were taken 30minutes after aircraft departure, again after three hours, and again after 14hours. For 10days prior to the flight, 10 participants received $300 \mathrm{mg}$ of an aesculus extract standardized to contain $50 \mathrm{mg}$ aescin, given twice daily, and nine received placebo. Results showed that the aesculus extract prevented an approximate $60 \mathrm{~m} 1$ swelling differential in all subjects, versus placebo. ${ }^{5}$

\section{Chronic venous insufficiency $(\mathrm{CVI})$}

Aesculus extract has been shown to significantly decrease the edema associated with CVI. Steiner and Hillemanns measured lower leg circumference (ankle and calf) and leg volume in ambulatory volunteers. Following 14days of treatment with $300 \mathrm{mg}$ of an aesculus extract standardized to contain $50 \mathrm{mg}$ aescin, given twice daily, significant reductions in leg volume were noted. A change in leg or ankle volume circumferences indicated that the volume reductions achieved resulted from decreased leg edema.

Many other clinical trials of CVI patients indicate that aesculus extracts result in a statistically significant decrease in edema. This is measured by venous occlusion plethymography, water volume displacement plethysmography, and measurement in the circumference of the foot, ankle, and leg. ${ }^{13-18}$

In a noteworthy 1998 article by Pittler and Ernst, the authors critically reviewed most of the current literature on the clinical use of aesculus. The authors concluded that horse chestnut extract was superior to placebo. In five of the review studies, aesculus was found to be as effective as another leading treatment for chronic venous insufficiency and edema. That leading treatment is O-(Bhydroxyethyl)-rutosides, a medicament obtained from extracting the flavonoids of buckwheat and various herbs. ${ }^{19}$

Other review papers on clinical studies have shown horse chestnut extract to be a real alternative in the treatment of patients with mild to moderate venous insufficiency, and systematic literature analysis's, evaluating clinical trials involving a total of 10,725 patients, showed benefits in leg volume, ankle and calf circumference, edema, pain, sensation of tension, swelling, leg fatigue/heaviness, calf cramps, and itching.

\section{Medicinal Preparations and Dosages}

Aesculus is often used with other heart and circulatory tonics (e.g., crataegus, linden, gingko, and yarrow), or combined with oak bark or witch hazel as a general styptic. ${ }^{3}$ It is also combined with butcher's broom (Ruscus aculeatus) and Gotu cola (Centella asiatica) for the treatment of cellulite, keloid scars, hematomas and easy bruising , dermatological conditions, telangectasias, anal fissures, perineal lesions, burns, and general wound regeneration. ${ }^{20-23}$

In modern European phytotherapy, the extract is prepared from the seeds and standardized to contain $16 \%$ to $21 \%$ aescin. ${ }^{6}$ This is taken orally as well as applied topically in the form of a salve, cream, or ointment. Topical use is recommended for pathological venous conditions, especially a condition known as chronic venous insufficiency (CVI), for edema and varicose veins, and for sore muscles to alleviate cramping. These treatments are widely available in Germany, and are now becoming popularized here in North America.

\section{Standardized extracts}

The Commission E monograph mentions horse chestnut preparation as Hippocastani semen (seed). It states, "A dry extract of the drug is manufactured from horse chestnut seeds (Aesculus hippocastanum L.), adjusted to a content of $16-20 \%$ triterpenoid glycosides (calculated as anhydrous aescin). ${ }^{6}$ Beginning with a dose of $90-150 \mathrm{mg} /$ day of this standardized preparation, and titrating to $35-$ $70 \mathrm{mg}$ maintenance dose, is the modern recommendation. 


\section{Infusions}

Pour one cup of boiling water into 0.2-1 gm of the dried, pulverized fruit. Steep in a covered vessel for 10-20 minutes. Two to three cups per day can be drunk, or it can be used as a topical application .

TINCTURE 1:3 (1gram crude drug delivered per $3 \mathrm{ml}$ dose of tincture). Can be utilized at a dose of 1-4m1 TID.3

\section{Topical preparations}

Aescin gel is typically applied TID over the afflicted area (varicosities, leg ulcers, telangectasias, swellings, ecchymosis, burns). It can also be used for hemorrhoids, by combining with witch hazel and butcher's broom on the area prn (i.e., when needed).

\section{Toxicity}

Internal use of the standardized aesculus extracts at the doses mentioned above is generally regarded as safe, according to Commission E. According to Michael Tierra, "the green outer casing of the fruit is poisonous and narcotic, but the toxic principles appear to be neutralized by cooking. Toxic symptoms include gastroenteritis, enlarged pupils, drowsiness, and flushing of the skin".

Throughout many of the clinical trials of aesculus, minor side effects were noted. These included gastrointestinal distress and nausea, light-headedness, headache, and allergic dermatitis reactions. ${ }^{7}$ In Germany, horse chestnut is approved by the Commission $\mathrm{E}$ as an OTC drug.

\section{Case study toxicity}

In an interesting case, a patient suffered a life-threatening rupture of the kidney in the presence of known renal angiomyolipoma (AML). She was taking Horse chestnut standardized extract. There was not a direct cause of the Horse chestnut standardized extract, but she underwent emergency embolization, with a successful outcome, almost bleeding to death. Because Horse chestnut standardized extract containing products are thought to be generally safe in the treatment of chronic venous insufficiency, it is important to be mindful of their potential anticoagulant properties and, therefore, their relative contraindication both in patients taking other anticoagulants and those with known renal AML. ${ }^{24,25}$

\section{Biography}

Dr. Eugene R. Zampieron, ND,MH,AHG has over 25years of experience as a licensed Naturopathic medical physician, professional herbalist, ethnobotanical researcher, botanical formulations inventor, professor, educator, internationally known author, lecturer, spokesman and radio personality.

Dr Z, as he is known to his students and audiences, was on the founding advisory board that helped firmly establish the University of Bridgeport College of Naturopathic Medicine as the first accredited naturopathic medical college on the US Eastern seaboard, and has trained hundreds of Naturopathic doctors and physicians internationally with his encyclopedic knowledge of plants and science-based natural medicine.

Dr Z was named one of the best and most innovative Naturopathic Doctors for 2016 by the Canadian Naturopathic Doctors Development Center and practices in Woodbury, CT and at the University of Bridgeport Naturopathic medical clinic.
He does regular radio on WPKN, WUSB and Gary Null' Progressive Radio Network, and hosts one of the longest running Reggae programs in the US on WUSB.FM, Rockin Iration, since 1982. He loves gardening, tropical plants, all things Jamaican, and is a black belt in multiple martial arts forms.

\section{Acknowledgments}

None.

\section{Conflicts of interest}

Author declares there are no conflicts of interest.

\section{Funding}

None.

\section{References}

1. Grieve M .A Modern Herbal. Chatham. London: Johnathan Cape LTD; 1931.pp.192.

2. Wren RC. Potters' Cyclopedia of Botanical/ Drugs\& Preps. C W. England: Daniel Company Ltd. Saffron Walden; 1998. pp. 147.

3. Kenner D, Requena Y. Botanical Medicine: A European Professional Perspective. USA: Paradigm Publications, Brookline; 1996.p.5.

4. Klemm J, Enghofer E. Influence of Venostatin on the blood flow in varicose veins of the lower extremities. Germany: Munch Med Wechr; 1982. pp. 179 .

5. Annoni F, Mauri A, Marincola F, et al. Arzneimittelforschung.1975;29(4) 672-675.

6. Blumenthal M. The Commission E Monograph. USA: American Botanical Council, Austin; 1997. pp. 118

7. Kreysel HW, Nissen HP, Enghofer E. A possible role of lysosomal enzymes in the pathogenesis of varicosities and the reduction in their serum activity by Venostatin. Vasa. 1983;12(4):377-382.

8. http://www.longwoodherbal.org/horsechestnut/horsechestnut.pdf

9. http://www.mothernature.com/

10. Felter MW. The Eclectic Materia Media, Pharmacology and Therapeutics. OR Eclectic Medical Publications, Portland. 1995. pp. 406.

11. Diehm C, Trampisch HJ, Lange S, et al. Comparison of leg compression stocking and oral horse chestnut seed extract (HCSE) therapy in patients with CVI. The Lancet.1996;347(8997):292-294.

12. Marshall M, Dormandy J. Oedema of long distance flights. Phlebology .1987;2:123-124.

13. Steiner M. Investigation of the edema-protective action of a venous therapeutic agent. Munch Med Wochenschr. 1986;31:55I.

14. Bisler L. 'The antiexhudative effect of horse chestnut extract (HCE) in patients with CVI. Dtsch Med Wsclr. 1986;35:1321.

15. Rudofsky. Demonstration of thee anti-edematous effect and the clinical efficacy of HCE in double blind study. Phlebologie Und Proktology. 1986;15:47.

16. Lohr E. Anti-oedema treatment in CVI with tendency to oedema. Much med Wschr. 1986;128(34):579.

17. Erdlen F. Clinical efficacy of Hemostasis retardation demonstrated in a double blind trial. Mcdwclt . 1989;40:994.

18. Cloree M. Study on the effect of a new vasoprotective Venostasin. Administered over a period of 2 months in CVI of the lower limbs. Directorate of Pharmacy and Medicaments. 1993;91:1574. 
19. Pittler MM, Ernst E. Horse chestnut seed extract for chronic venous insufficiency: a criteria based systematic renew. Arch Derm. 1998;134(11):1386-1360.

20. Murray M. Lecture notes. Botanical Medicine 2. Bastyr University, Seattle, USA.1988.

21. Tierra M Planetary Herbology. Santa Fe, Lotus Press, USA. 1988. pp. 337.

22. Morien K .Horse chestnut effective in chronic venous insufficiency. USA: Herbal Gram; 1999.
23. Suter A, Bommer S, Rechner J. Treatment of patients with venous insufficiency with fresh plant horse chestnut seed extract: a review of 5 clinical studies. Adv Ther. 2006;23(1):179-190.

24. Snow A, Halpenny D, McNeill G, et al. Life-threatening rupture of a renal angiomyolipoma in a patient taking over-the-counter horse chestnut seed extract. J Emerg Med. 2012;43(6):e401-e403.

25. Siebert U, Brach M, Sroczynski G, et al. Efficacy, routine effectiveness, and safety of horse chestnut seed extract in the treatment of chronic venous insufficiency. A meta-analysis of randomized controlled trials and large observational studies. Int Angiol. 2002;21(4):305-315. 